likely to be misleading. This too only represents an arithmetical result, and signifies that as in the series of twenty-two observations there is an average departure of $\pm 5^{\circ} 2$ inches from the mean of all the measurements, the probability is that this mean will be within \pm 0.94 inch of the truth, so far as those measurements are to be trusted.

For these reasons I ain quite unable to follow the arguments by which it is sought to connect the amounts of these two "probable errors," or to see how they can in any way indicate "the relative probability of this particularvariation being the result of a periodic law, and of its being a mere fortuitous series of variations from a constant average.

Neither does there appear to be any justification for assuming that the relative probability of the truth of two hypotheses is represented by the inverse ratios of the probable errors of results derived from them. Still less is there any ground for saying that because the particular series of quantities under discussion relates to a period of twenty-twoyears, the relative probability just alluded to is thereby increased to the twenty-second power of that ratio, or from about $I \frac{1}{3}$ to $I$, to 655 to $I$. It is no doubt true that if the probability of an event occurring once be represented by the fraction $\frac{\mathbf{I}}{x}$, the probability of its recurring $n$ times in succession will be represented by $\left(\frac{\mathbf{I}}{x}\right)^{n}$; but I fail to see how this affects the question at issue. Richard STRACHEY. July I I, I 887 .

\section{Is Cold the Cause of Anticyclones?}

IN a review of Loomis's papers in this volume of NATURE, p. 2, occur the following sentences:- "While all, or nearly all, of the high pressure of anticyclones may be accounted for by the very low temperatures which overspread the same region at the same time along with the resulting upper currents concentrating upon them from adjoining cyclonic regions, it is quite different with the low pressures of cyclones. In the case of cyclones the problem is complicated by the strong winds, the copious precipitation, and the ascending currents, which affect the results in ways which no physicist has yet been able to explain."

This induction of Loomis's, that anticyclones are largely the result of cold, which the reviewer here repeats, is in entire opposition to the deductive views of Ferrel, and I think the discrepancy is to be found in the method used by Loomis in drawing his inductions. In order to investigate the cause of anticyclones, Loomis selected only decided areas of high pressure, and as a consequence his data were almost entirely confined to the winter months, when the temperature accompanying anticyclones is always low. If, however, he had selected more moderate anticyclones, he would have found that in summer anticyclones in the United States are sometimes accompanied by intense heat $\left(90^{\circ} \mathrm{F}\right.$. or more). This is especially so in periods of drought. Under these conditions the approach of a cyclone with rain brings a most refreshing cooling. Furthermore, Hahn, attacking the problem by a different method, has obtained results apparently directly opposed to this induction of Loomis. Hahn made a careful study and comparison of the observations obtained last autumn and winter on the Sonnblick and at adjacent mountain and valley stations (see Meteorologische Zeitschrift, February and April 1887). One of the most marked results found was that at heights exceeding rooo metres above sea-level there was an increase of temperature during anticyclones, while a decreased temperature was only found in valleys and near the general level of the earth's surface. Hahn's average results show that the temperature on the Sonnblick, height 3090 metres, rose from an average of $-16^{\circ} .4 \mathrm{C}$. at the average barometric pressure of $509.1 \mathrm{~mm}$. to $-7^{\circ} .7 \mathrm{C}$, at the barometric pressure of $529^{\circ} 3 \mathrm{~mm}$, ; while at the same time the average temperature at Schafberg, height 1776 metres, rose from $-9^{\circ} \circ \mathrm{C}$. to $+\mathrm{I}^{\circ} .4 \mathrm{C}$. ; but on the contrary at Zell-a-See, height 754 metres, the average temperature fell from $-5^{\circ} \cdot 9 \mathrm{C}$. to $-8.9 \mathrm{C}$. These results, which show that the larger portion of the atmosphere is warmed instead of cooled within the area of an anticyclone, seems entirely destructive of Loomis's hypothesis that the cooling of the air near the earth's surface is the chief cause of the anticyclone. Hahn's results, however, indicate that the cooling of the air near the earth's surface does increase the pressure somewhat. Thus in October I886 the barometric minimum occurred at all the stations, both mountain and valley, on the 17 th ; while the barometric maximum occurred at all of the stations on the 3oth. When the difference in pressure between the mountain stations at the time of barometric minimum was compared with the difference in pressure between the same stations at the time of barometric maximum, it was found almost exactly the same; but the difference in pressure between the valley stations and the mountain stations was about $5 \mathrm{~mm}$. greater at the time of maximum pressure than at the time of minimum pressure. Hahn refers this greater range of pressure at the valley stations to the decreased temperature at valley stations during anticyclones, but this still leaves a range of pressure of nearly $20 \mathrm{~mm}$., which the decreased temperature entirely fails to explain. These results of Hahn are in entire accord with the results obtained at Blue Hill Observatory ( 640 feet above sea), as compared with Mount Washington and with stations near sea-level, which indicate that the cooling in anticyclones is almost entirely confined to within a few hundred feet of the earth's surface (see Science, vol. viii. pp. 233 and 281 ).

In the light of these facts, it seems more reasonable to assume that the warmth found on mountains and the cold in valleys, accompanying anticyclones, are the result, rather than the cause, of anticyclones. Such researches as those of Langley on the solar heat, and of Hahn on the distribution of temperature pressure, \&c., in different planes of the atmosphere, indicate that the effect of the sun's heat on the atmosphere is far more complex than some of our text-books on meteorology would have us believe ; and instead of the cause of anticyclones being as simple as the reviewer of Loomis's article states, it seems probable that we shall understand the phenomenon of the anticyclone only when we master the problem of the cyclone.

Blue Hill Observatory, Boston, Mass., U.S., June 28.

\section{Physiological Selection.}

I AM perhaps in a position to contribute something practical to the discussion upon Mr. G. J. Romanes's proposal of physiological selection as an improvement upon Darwin's natural selection.

I failed to meet with Mr. Romanes's paper in the Journal of the Linnean Society, and I confess that I did not gain a very clear idea of what he meant by physiological selection, until I read his article in the Nineteenth Century for January. His main difficulty appears to be the intercrossing with parent stock, which he thinks would prevent the survival of any varieties naturally selected to become species. Now, my Australian bush experience of the habits of animals and birds satisfies me that this difficulty is mainly, if not entirely, imaginary, and that Nature amply provides against the supposed intercrossing. Any person who has observed the habits of semidomesticated stock, such as horses and cattle, can scarcely fail to know that migration is a general practice of one sex, and a frequent one of the other. The old always hunt the young males and strangers entirely away to form herds and families of their own, and thus the supposed intercrossing is by one sex at least effectually obviated. But it is also frequently the case that young fillies and heifers, at the same season, take to wandering, for less evident reasons, far from their accustomed haunts, scores of miles, after which they will stop, and attach themselves to another herd and locality as tenaciously as their parents remain in theirs. This of course further tends to prevent intercrossing with parent stocks.

I cannot but think that Mr. Romanes's anxiety to find a solution of his difficulty has led him into serious mistakes, which vitiate his treatment of the subject. For instance, he says (page 59, Nineteenth Century for January), "The hypothesis of physiological selection sets out with an attempted proof of the inadequacy of natural selection, considered as a theory of the origin of species." I was out walking yesterday when I read this, and I wrote in the margin, "The theory of natural selection is one, not of the origin of species at all, but of the preservation of particular varieties." On reaching home, I referred to the "Origin of Species" (4th edition, 1866), and was certainly pleased to fiud that I had adopted Darwin's precise words repeated in several places (see pages 7I, 9r, I23, \&c.). At page 9I he says :- "Some writers have misapprehended or objected to the term natural selection. Some have imagined that natural selection induces variability; whereas it implies only the preservation of such varieties as occur, and are beneficial under 